\title{
El espacio arcádico-idílico en la España de Spanish Affair
}

\author{
Luis N. Sanguinet | ln.sanguinet@alumnos.urjc.es \\ Universidad Rey Juan Carlos
}

Palabras clave

"Carmen Sevilla"; "coproducción”; "España”;

"EEUU”; "folklore”; "identidad cultural”

\section{Sumario}

1. Introducción

2. Estado de la cuestión y metodología

3. Análisis del espacio

3.1 Modos de espacio

3.2 Exteriores e interiores

3.3 Presentación de personajes

3.4 Propósito del espacio

3.5 Relación entre espacios y evolución de personajes

4. Condicionantes de producción

5. Discusión

6. Conclusiones

7. Bibliografía

8. Filmografía

\section{Resumen}

A mediados de los años cincuenta se rodó en España la coproducción Aventura para dos (Spanish Affair, Don Siegel, 1957) con Carmen Sevilla y Richard Kiley, que se estrenó internacionalmente, mientras estaba en vigor un embargo de exportaciones de Hollywood a España. Representantes del Gobierno en el extranjero se quejaron a organismos españoles por permitir una producción extranjera en territorio español que según sus testimonios dañaba la imagen del país. Tomando como herramienta el análisis de espacios en films turísticos españoles de Nieto Ferrando, Rey-Reguillo y Afinoguenova, este trabajo estudia las características de este film que configuran España como espacio arcádico-idílico. Los resultados del análisis y la comparación con el artículo mencionado su-

gieren que las quejas, aunque acertadas sobre el folclore y tradicionalismo representados, no serían consecuentes con la postura oficial del gobierno. Ese imaginario era la tendencia en films españoles que promocionaban el territorio nacional como destino turístico, que proliferaban en los años cincuenta y concordaban con el Spain is different promovido por organismos oficiales desde inicios de dicha década.

\section{Cómo citar este texto:}

Luis N. Sanguinet (2022): El espacio arcádico idílico en la España de Spanish Affair, en Miguel Hernández Communication Journal, Vol. 13 (1), pp. 59 a 79. Universidad Miguel Hernández, UMH (Elche-Alicante). DOI: 10.21134/mhjournal.v13i.1449 


\title{
The arcadian-idyllic place in the Spain of Spanish Affair
}

\author{
Luis N. Sanguinet | ln.sanguinet@alumnos.urjc.es \\ Universidad Rey Juan Carlos
}

Keywords

"agenda setting"; "media shielding"; "monarchy";

"Juan Carlos I"; "television"

Summary

1. Introduction

2. State of the art and methodology

3. Place Analysis

3.1 Kinds of place

3.2 Exteriors and interiors

3.3 Presentation of characters

3.4 Purpose of place

3.5 Relationship between place and character evolution

4. Production constraints

5. Discussion

6. Conclusions

7. Bibliography

8. Filmography

\section{Abstract}

In the mid-1950s, the co-production Spanish Affair (Don Siegel, 1957), starring Carmen Sevilla and Richard Kiley, was filmed in Spain and premiered internationally, while a Hollywood exports embargo to Spain was in force. Government representatives abroad complained to Spanish organizations for allowing a foreign production in Spanish territory, which according to their testimonies damaged the country's image. Taking as a tool the analysis of places in Spanish tourist films by Nieto Ferrando, del Rey Reguillo and Afinoguenova, this paper studies the characteristics of this film that configure Spain as an arcadian-idyllic place. The results of the analysis and the comparison with the aforementioned article suggest that the complaints, although accurate about the folklore and traditionalism represented, would not be consistent with the official position of the government. This imaginary was the trend in Spanish films that promoted the national territory as a tourist destination, which proliferated in the fifties and coincided with the slogan Spain is different promoted by official organizations since the beginning of that decade.

Luis N. Sanguinet (2022): El espacio arcádico idílico en la España de Spanish Affair, en Miguel Hernández Communication Journal, Vol. 13 (1), pp. 59 a 79. Universidad Miguel Hernández, UMH (Elche-Alicante). DOI: 10.21134/mhjournal.v13i.1449 


\section{Introducción}

El film Aventura para dos (Spanish Affair, Don Siegel, 1957) narra la visita a España del arquitecto estadounidense Merrit Blake (Richard Kiley), para convencer a unos socios sobre sus diseños para un complejo hotelero de estética minimalista, que contrastaría con el entorno español. Su amigo Carlos Sotelo (Jesús Tordesillas), le presta los servicios de Mari Zarubia (Carmen Sevilla), secretaria de raíces gitanas, como guía y traductora. Ambos son perseguidos por Antonio (José Guardiola), prometido de Mari desde su infancia. El dilema vertebrador del film es un conflicto entre tradición y modernidad que afecta a ambos protagonistas: Merrit defiende un edificio moderno para una España tradicional y Mari quiere renunciar al matrimonio apalabrado, vinculado a su tradición étnica, al tiempo que se enamora del estadounidense.

Cuando el film se estrenó en el extranjero, representantes del gobierno español formalizaron quejas desde Londres y Nueva York al Ministerio de Asuntos Exteriores (MAE), por haber autorizado guion y rodaje de un film que daba una imagen nefasta de España y culpando de la baja calidad aludida en las críticas londinenses a una supuesta "pretensión de autenticidad” (AGA (3) 121.2 36/04769). La Dirección General de Cinematografía y Teatro (DGCT) exigió a la productora Cinematografía Española Americana (CEA) confirmación del cumplimiento de las exigencias de censura. La productora se defendió confirmándolo y desentendiéndose de la calidad del film. "La idea inicial de esta coproducción surgió del deliberado propósito de llevar a la pantalla bellos paisajes y monumentos españoles" (AGA (3) $121.236 / 04769)$.

Para confirmar la pertinencia de aquellas quejas, el presente texto analiza el imaginario español representado en el film. Como herramienta sirve la publicación de Nieto Ferrando, del Rey Reguillo y Afoniguenova (2015) que propone un método para analizar el espacio como producto emplazado en la estructura narrativa y dramática en films españoles con finalidad turística entre 1951 y 1977, que proliferaron a raíz de la creación en 1951 del Ministerio de Información y Turismo (MIT), el cual controlaba la DGCT y fomentaba el turismo como vía de desarrollo.

\section{Estado de la cuestión y metodología}

A inicios de los años cincuenta, por la tensión internacional de la Guerra Fría, España entró en los intereses geopolíticos de Estados Unidos. Ambos gobiernos apartaron sus diferencias, incluida la exclusión de España del Plan Marshall, firmando en 1953 los Pactos de Madrid, que el redactor militar del New York Times describió como un "matrimonio de conveniencia" (Viñas, 2003: 237). Ese mismo año desde el MIT se planteó mediante el Plan Nacional de Turismo la promoción turística de España para solventar la precariedad económica. El acercamiento de Estados Unidos ayudaba al gobierno español en su empresa turística y al estadounidense, en su agenda política.

Cuando la histeria McCarthista fue ganando terreno entre los congresistas y parte de la opinión pública, el acercamiento a un régimen como el de Franco se hizo menos 
desagradable. Al fin y al cabo, el anticomunismo del gobierno español estaba garantizado, y era incluso más firme que el de muchos de los aliados europeos (Montero y Niño, 2013: 159).

Este contexto político es tenido en cuenta para considerar su influencia en las quejas de los representantes franquistas sobre el film. Entre las primeras negociaciones binacionales de la década está el acuerdo cinematográfico del 1 de marzo de 1952 sobre las condiciones de importación de cine de Hollywood, que rigió hasta el 24 de agosto de 1955, cuando la Motion Picture Export Association of America (MPEAA), representante de las majors, decretó un embargo indefinido de exportaciones a España. Pablo León (2010) recoge los vaivenes de todas las negociaciones implicadas y señala que el detonante decisivo para el embargo fue la cuota de pantalla de cine estadounidense en carteleras españolas, que permaneció en 1x5 en lugar del $1 \times 4$ que pedía la MPEAA.

La MPEAA buscaba repetir los efectos del boicot anterior en 1951 "creando una crisis en el sistema de fomento y un colapso en la industria española” (Díez Puertas 1996: 37). Pero del embargo de 1955 la MPEAA no ganó nada, pues cuando finalizó seguían vigentes todas las condiciones que lo habían generado (León, 2010, p. 373). Como señala León (2010), la MPEAA fue la principal perjudicada por el embargo, pues las productoras independientes, las disidencias de United Artists y Republic y el cine europeo mitigaron los efectos (León, 2010: 346). El gobierno español "salió mejor parado, (...) sin que España ni el cine español se beneficiaran de ello" (León, 2010: 441), dado que la DGCT, parte negociadora española, no atendía las demandas de la industria española.

Spanish Affair fue rodada en inglés en verano de 1956 y estrenada internacionalmente en octubre de 1957, con el embargo en vigor. En cuanto al estreno español, todavía no estaba hecho el doblaje, pues Paramount creó la productora Nomad para no verse afectada por el embargo e intentar conseguir la licencia de doblaje, las filiales de las majors no recibieron ninguna durante el embargo (Leon, 2010: 350). Dado que la legislación franquista solo admitía estrenos en español, previa concesión de licencia de doblaje (Díez Puertas, 1995: 12), sin doblaje no había estreno. El bloqueo terminó el 1 de abril de 1958, con la MPEAA y la DGCT firmando un nuevo acuerdo. Ya sin el bloqueo en vigor se grabó el doblaje en verano de 1958 (Sevilla, 1993: 77-78) y en septiembre llegó el estreno español.

La recuperación de relaciones con Estados Unidos supuso un cambio estratégico para España. Es significativo el nuevo montaje de 1951 para Raz̧a (J. L. Sáenz de Heredia, 1942), eliminando el antiamericanismo de la versión original, donde Estados Unidos era partícipe en la pérdida de Cuba. Kepa Sojo aborda el cambio de imagen de Estados Unidos en el cine español a partir de los pactos de Madrid:

(...) a consecuencia de los Acuerdos bilaterales y al éxito de Bienvenido Mister Marshall podemos decir que se produce una eclosión de un tipo de cine generalmente de comedia y algunas veces ambientado en el ámbito rural, donde aparece esta nueva visión amable de los americanos refrendada en el ya citado acuerdo hispano-norteamericano (Sojo, 2011: 43). 
Esta visión amable encajaba con la americanización, difusión de valores colaborativos de Estados Unidos con Europa en ciencia, tecnología, gestión empresarial y finanzas (Barjot, 2005: 168). En films como Todo es posible en Granada (José Luis Sáenz de Heredia, 1954), Aqui hay petróleo (Rafael J. Salvia, 1955), Horas de pánico (Donald Taylor, 1957), Elpuente de la paz. (Rafael J. Salvia, 1958) y Un americano en Toledo (Carlos Arévalo, 1960). Los personajes estadounidenses son siempre amistosos y llegaban para compartir avances tecnológicos, científicos o económicos.

Como rodaje y estreno internacional sucedieron en el momento más conflictivo en las negociaciones entre gobierno español y MPEAA (León, 2010: 334), sería comprensible que el ambiente influyera tanto en las quejas como en su recorrido administrativo, sospechando desde el MAE un rodaje no ajustado al guion autorizado. La implicación de Paramount como distribuidora internacional convertía a Spanish Affair en un film con posibilidades comerciales fuera de España. Esto es importante, pues de las películas españolas con intención turística de los años cincuenta y sesenta, "muy pocas tuvieron una vida comercial fuera de España, lo que implica no alcanzar el público extranjero, el más interesado por el país como destino turístico" (Nieto Ferrando, Rey-Reguillo y Afinoguenova, 2015: 586).

La promoción del territorio español alegada por CEA permite, con el fin de corroborar las quejas, analizar el espacio español representado en Spanish Affair como si fuera producto emplazado. Para identificar las características del espacio sirve la catalogación de Vale (1986: 49) según tipo, clase, propósito, relación y ubicación. Vale es referencia importante en la investigación de Nieto Ferrando, del Rey Reguillo y Afinoguenova, que es la herramienta principal para el análisis espacial de este texto, pues plantean un método para estudiar el espacio español en films turísticos coetáneos del aquí estudiado.

Los resultados recogidos se compararán con los de Nieto Ferrando et al. (2015: 607), pues según su estudio en el cine español de mediados de los cincuenta predominaba el espacio arcádico e idílico como imagen del territorio español. Para completar la perspectiva se incluyen testimonios sobre las condiciones de la producción, en busca de indicios que pudieran reafirmar o refutar las quejas. Esto permite esclarecer si Spanish Affair es un film que caricaturiza a España desde la mirada extranjera, o si se asemeja a los films que promocionaban el territorio español, permitidos y promovidos desde el MIT.

\section{Análisis del espacio}

Las ubicaciones del film son todas españolas y conforman un recorrido por cuatro ciudades principales que estructuran la historia: Madrid, Segovia, Barcelona y Toledo, pasando por Tossa de Mar, un pueblo de la Costa Brava. Cuando Merrit llega a Madrid, su amigo Sotelo le informa del rechazo de su proyecto por parte de los otros socios, quienes se encuentran de vacaciones en Segovia y Barcelona: el Conde Ribera tiene una finca a las afueras de Segovia y el Sr. Oliva descansa en su caserón de Tossa de Mar. Merrit viaja para convencerlos de reconsiderar sus diseños, sin conseguirlo. Terminado el periplo, Mari se va con Antonio a un poblado gitano, luego visita a su padre en Toledo y Merrit va allí a su encuentro para confesarle su amor. 


\section{MHJournal Vol. 13 (1) | Año 2022 - Artículo no 3 (196) - Páginas 59 a 79 - mhjournal.org}

Según la catalogación de Vale (1986: 49) el tipo de espacio es el lugar concreto en que se desarrolla una escena, la clase o modo supone las cualidades que lo adjetivan, el propósito determina las acciones para las que el espacio es propicio, la relación con los personajes define cómo se relaciona el espacio con estos y la ubicación se refiere a la localización geográfica dentro de la cual se circunscribe el tipo de espacio. La tabla 1 clasifica los espacios del trayecto, indicando ubicación y tipo, tiempo en pantalla, si son exteriores o interiores y su modo según la clasificación de Nieto Ferrando, del Rey Reguillo y Afinoguenova: arcádico, idílico, moderno, fantástico, exclusivo y agresivo.

\subsection{Modos de espacio}

Para catalogar los modos de espacio Nieto Ferrando, Rey-Reguillo y Afinoguenova (2015: 607) ofrecen una "tipología de los espacios turísticos en función de los valores intangibles (...) que se le vinculan a través de la puesta en escena, de la puesta en cuadro y de la interacción que [el espacio] establece con los personajes", definiéndolos como: arcádico, idílico, moderno, fantástico, exclusivo y agresivo. Los resultados de la tabla 1 muestran el predominio de espacios arcádico-idílicos. El espacio turístico idílico sería "fruto de sus características físicas (playas, calas vírgenes, lugares monumentales, etc.) y del uso de espacio por parte de los personajes"; y el espacio arcádico estaría "vinculado al pasado, a la tradición o al folclore. Puede estar vinculado tanto al hedonismo, como al atraso social" (Nieto Ferrando, Rey-Reguillo y Afinoguenova, 2015: 597). Cabría mencionar que el espacio agresivo sería aquel que, sea por su masificación o por suponer algún peligro u amenaza, los personajes intentar huir de él (Nieto Ferrando, Rey-Reguillo y Afinoguenova, 2015: 590).

Tabla 1. Modos de espacio del trayecto

\begin{tabular}{|c|c|c|c|c|c|c|c|c|c|}
\hline \multirow{2}{*}{ Ubicación } & \multirow{2}{*}{ Tipo } & \multirow{2}{*}{ Segundos } & \multirow{2}{*}{ Ext-Int } & \multicolumn{6}{|c|}{ Modo } \\
\hline & & & & Arc. & Idíl. & Mod. & Fan. & Excl. & Agr. \\
\hline \multirow{9}{*}{ Madrid } & Museo del Prado & 174 & Int & $*$ & $*$ & & & * & \\
\hline & Aeropuerto de Barajas & 60 & Ext & $*$ & * & $*$ & & * & \\
\hline & Plaza de Cibeles & 3 & Ext & * & $*$ & & & & \\
\hline & Taxi & 121 & Int & & * & $*$ & & & \\
\hline & Despacho de Sotelo & 290 & Int & $*$ & $*$ & & & * & \\
\hline & Paseo del Prado & 32 & Ext & & $*$ & & & & $*$ \\
\hline & Calle de bares & 10 & Ext & * & & & & & * \\
\hline & Bar con tablado subterráneo & 169 & Int & * & & & & & * \\
\hline & Puerta de hotel & 62 & Ext & $*$ & $*$ & $*$ & & $*$ & \\
\hline Indefinido & Carretera & 53 & Ext & * & * & & & & \\
\hline \multirow{2}{*}{ Madrid } & Fuente de Neptuno & 19 & Ext & * & & & & & $*$ \\
\hline & Cartel & 3 & Ext & * & & & & & $*$ \\
\hline Indefinido & Carretera & 28 & Ext & $*$ & $*$ & & & & \\
\hline \multirow{3}{*}{ Segovia } & Acueducto & 143 & Ext & $*$ & $*$ & & & & \\
\hline & Alcázar & 41 & Ext & $*$ & $*$ & & & & \\
\hline & Dehesa del Conde Ribera & 696 & Ext & $*$ & $*$ & & & * & $*$ \\
\hline
\end{tabular}




\begin{tabular}{|c|c|c|c|c|c|c|c|c|}
\hline Indefinido & Carretera & 6 & Ext & * & & & & \\
\hline \multirow{4}{*}{ Barcelona } & Vista general & 10 & Ext & $*$ & $*$ & $*$ & & \\
\hline & Hotel & 84 & Int & & $*$ & $*$ & $*$ & \\
\hline & Casco antiguo & 939 & Ext & $*$ & * & & & $*$ \\
\hline & Habitación de Mari & 34 & Int & & * & $*$ & $*$ & \\
\hline Costa Brava & Carretera peligrosa & 260 & Ext & $*$ & & & & * \\
\hline \multirow{6}{*}{ Tossa de Mar } & Mirador de casa de Oliva & 220 & Ext & $*$ & * & & $*$ & \\
\hline & Paseo marítimo & 95 & Ext & $*$ & $*$ & & & \\
\hline & Playa & 395 & Ext & $*$ & $*$ & & & \\
\hline & Paseo junto al Castillo & 145 & Ext & $*$ & $*$ & & & \\
\hline & Catedral en ruinas & 134 & Ext & $*$ & $*$ & & & $*$ \\
\hline & Acantilado & 56 & Ext & $*$ & & & $*$ & \\
\hline Indefinido & Pablado gitano & 93 & Ext & * & & & & \\
\hline \multirow{2}{*}{ Toledo } & Vista general & 5 & Ext & $*$ & $*$ & & $*$ & \\
\hline & Cigarral del padre de Mari & 255 & Ext & * & $*$ & & & \\
\hline Tossa de Mar & Bar & 265 & Int & * & $*$ & & & \\
\hline \multirow{3}{*}{ Toledo } & Callejones y tejados & 337 & Ext & $*$ & $*$ & & & $*$ \\
\hline & Mezquita en ruinas & 232 & Int abierto & $*$ & & & & $*$ \\
\hline & Orilla del Tajo & 60 & Ext & $*$ & $*$ & & & \\
\hline
\end{tabular}

Fuente: elaboración propia

En Spanish Affair se produce esa doble vinculación del espacio arcádico al hedonismo y al atraso social, dependiendo de la clase social. En clases altas lo arcádico y tradicional son exclusivos, distinguen socialmente: Sotelo tiene un Greco en su despacho, el Conde Ribera tienta toros bravos en su dehesa, el Sr. Oliva tiene un mirador con vistas a la playa y castillos en ruinas y el padre de Mari un cigarral con vistas de todo Toledo. Estos son arcádico-idílico-exclusivos. En clases bajas, en cambio, llegan a ser agresivos, por la presencia de Antonio. Mari es llevada forzosamente al tablado por los secuaces de Antonio y en el poblado gitano se unen folclore y pobreza, con niños bailando flamenco y pidiendo limosnas. En ambos casos aparecen turistas disfrutando del folclore, mostrando que la agresividad afecta solo a los protagonistas.

La agresividad se extiende a espacios en que Antonio persigue a la pareja: por la carretera al salir de la dehesa segoviana, por las calles de Barcelona y en la persecución final por Toledo, donde protagonista vence a Antonio. Hay aspectos que pueden resultar puntualmente agresivos como el intento de estafa de un vendedor ambulante en Barcelona, que es evitado por Mari; y las curvas peligrosas de Costa Brava, que propician un accidente. Salvo esa excepción los trayectos entre ciudades son arcádico-idílicos, disfrutados por los protagonistas, a pesar de mostrar signos de atraso tecnológico: son escenas de carreteras rurales, a menudo desérticas, con campesinos llevando ganado y carretas tiradas por caballos, obstaculizando el tránsito.

Dentro de las ciudades lo arcádico-idílico se activa por construcciones vinculadas al pasado histórico. El acueducto y el Alcázar remiten a una concepción hedonista del territorio espa- 
ñol. En Tossa de Mar la playa está rodeada de catedrales y castillos en ruinas y en Toledo, el casco antiguo acoge la persecución final. Contrasta el tiempo dedicado a Tossa, Segovia y Toledo, espacios arcádicos con el de las ciudades más modernas, Madrid y Barcelona.

\subsection{Exteriores e interiores}

Las palabras de disgusto del embajador español resaltaban ese tipo de detalles, acerca de la imagen poco moderna de España en Spanish Affair:

No se explica si el objetivo de su viaje obedece a que en nuestro país no existen hoteles, o a que no haya arquitectos capaces de construirlos. En todo caso, esta idea excluye a priori el uso de exteriores en las ciudades, ya que, si se utilizasen, la falsedad de la idea quedaría de manifiesto (AGA (3) 121.2 36/04769).

La presencia de arquitectos españoles es explicada y demostrada cuando Sotelo propone a Merrit modificaciones para reducir el contraste de sus planos con el entorno. Es más importante la mención sobre la omisión intencionada de exteriores, que corroboraría esta crítica de Argentina:

Un voto de gracias a los editores de la película que con cariñoso cuidado han eliminado, en las ciudades modernas, toda imagen de progreso o contemporaneidad, a fin de destacar bien el guitarreo, la gitanería, las cañas de vino y otras características de la auténtica vida de España (León, 2010: 354).

Tabla 2. Tiempo en pantalla de las localizaciones

\begin{tabular}{|c|c|c|c|}
\hline Ciudad & Segundos totales & En exterior & En interior \\
\hline Madrid & 943 & 189 & 754 \\
\hline Segovia & 980 & 980 & \\
\hline Barcelona & 1.067 & 949 & 118 \\
\hline Tossa de Mar & 1.444 & 1.179 & 265 \\
\hline Poblado & 93 & 93 & \\
\hline Toledo & 889 & 657 & 232 \\
\hline Carreteras & 347 & 347 & \\
\hline
\end{tabular}

Fuente: elaboración propia

A la falta de protagonismo de las ciudades más modernas Madrid y Barcelona, se añade la atención sobre el uso de exteriores en las mismas. Comparando con el resto del film, los exteriores representan el 86,75\% en las localidades que no son Madrid ni Barcelona. No resulta particular Barcelona, cuyos exteriores representan el 88,94\%, mientras que el caso de Madrid sí es llamativo con apenas un 20,04\% de exteriores. Debe tenerse en cuenta en qué condiciones estos exteriores e interiores influyen en la construcción del espacio arcádico-idílico. 
Figura 1. Fotogramas de Spanish Affair (Don Siegel, 1957)

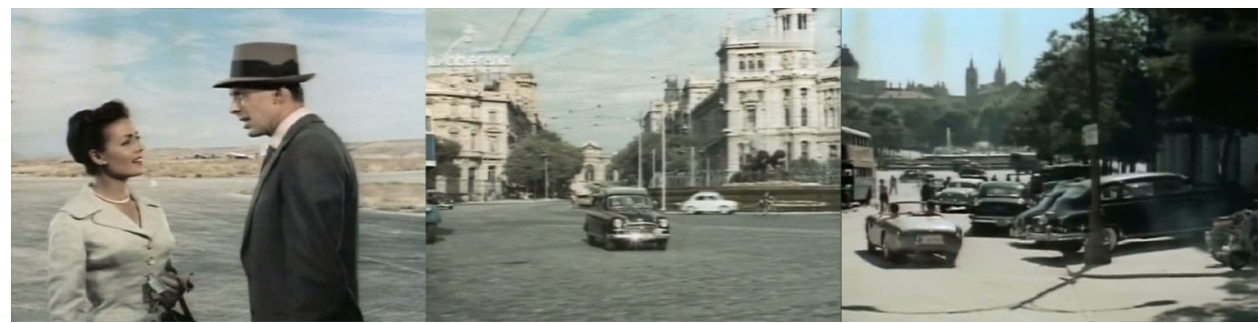

Fuente: Paramount Pictures Corporation (C)

En cuanto a los exteriores madrileños (Fig. 1) la escena del aeropuerto, el más moderno espacio de todo el film, se resuelve en la pista de aterrizaje con un fondo desértico. El trayecto en taxi es recogido en un plano interior del vehículo, donde la atención la acaparan los personajes y no la cantidad de coches del exterior. Un plano situación de Madrid que dura apenas tres segundos, muestra Cibeles y el Palacio de Comunicaciones de fondo.

Lo más similar a un plano general madrileño es la salida del hotel, con el moderno descapotable conducido por el estadounidense contrasta con el resto de vehículos y un vetusto fondo: la fuente de Neptuno, árboles y tejados, tras los cuales destaca la Iglesia de san Jerónimo el Real del siglo XVI. Es mucho mayor el tiempo dedicado a los interiores madrileños (Fig. 2): el Museo del Prado, el despacho de Sotelo y el bar de Antonio, que conjugan lo arcádico por medio de la tradición artística.

Figura 2. Fotogramas de Spanish Affair (Don Siegel, 1957)

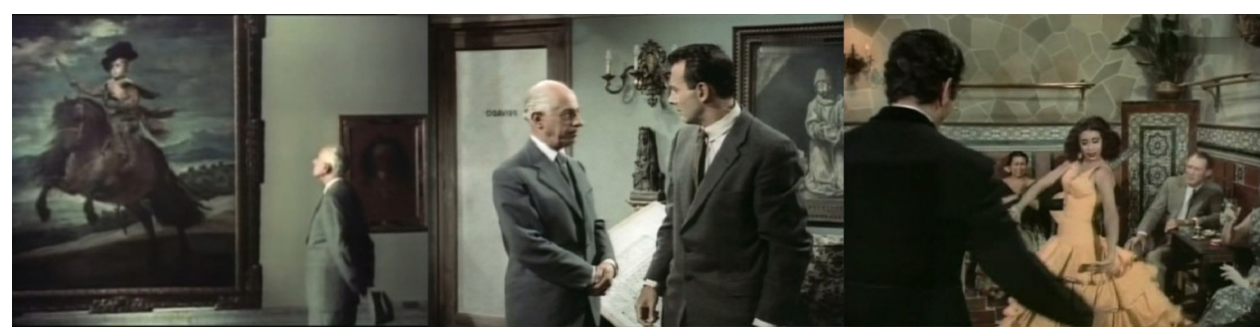

Fuente: Paramount Pictures Corporation (C)

En Barcelona (Fig. 3) hay una panorámica de tres segundos da más información del puerto que de los edificios céntricos. Los interiores se limitan a escenas del hotel y la escena exterior se desarrolla íntegra en el casco antiguo con calles adoquinadas, y planos cortos que parecen estrechar los pasajes. En la plaza barcelonesa donde la pareja baila participando en una sardana, los contra-planos son de edificios de pocas plantas y construcción antigua. 
Figura 3. Fotogramas de Spanish Affair (Don Siegel, 1957)

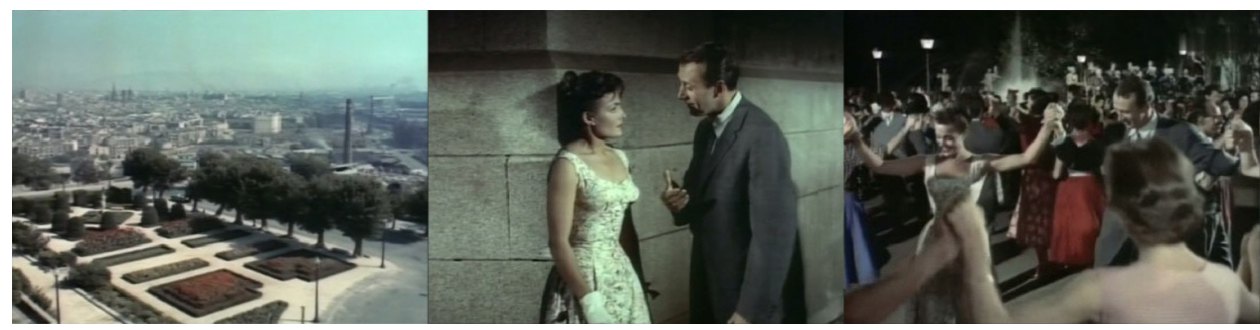

Fuente: Paramount Pictures Corporation (C)

La falta de planos generales de Madrid y Barcelona contrasta con la atención dada a las construcciones de Segovia y Toledo y más aún con el pueblo costero Tossa de Mar, cuyos idílicos paisajes son los que más tiempo ocupan. Solo sus exteriores suponen más del 20\% del film. El predominio de construcciones antiguas y en ruinas y de paisajes rurales y desérticos reflejo del atraso social construyen un imaginario arcádico que, acompañado de elementos folclóricos, ratificaría los comentarios del embajador.

\subsection{Presentación de personajes}

Los primeros espacios sirven para presentar a los personajes principales. En el Museo del Prado, tras la secuencia de créditos con obras del Greco, Velázquez y Goya, se presenta a los personajes españoles, Sotelo y su secretaria Mari. Éstos mantienen una conversación laboral en los pasillos del museo, como si este espacio fuera una extensión de la oficina. Esto presenta a personajes españoles que aprovechan su pausa en horario laboral para contemplar obras de arte. A continuación, en el aeropuerto de Barajas es presentado Merrit, recibido por Mari a pie de pista en planos siempre exteriores. Un elemento moderno como el avión difiere del entorno arcádico con fondo desértico. Esta antinomia sintetiza el contraste del entorno español y Merrit, desde su primera aparición.

Los problemas del protagonista son explayados en el despacho de Sotelo, en un entorno con muebles antiguos y artículos de valor, incluida una pintura del Greco (0:08:15): San Francisco de Asís y el hermano León meditando sobre la muerte. Dadas las numerosas versiones del tema que salieron del taller del Greco, la elección de este cuadro además de definir el nivel adquisitivo de Sotelo con tópicos de la burguesía castiza, es un detalle verosímil y plausible, (Martinez-Burgos y Mingo, 2013: 197-198). Después llega la presentación del antagonista Antonio, prometido de Mari. Dos hombres escoltan forzosamente a Mari llevándola a un bar madrileño, pasando por escaleras y pasillos estrechos, hasta un tablado subterráneo donde Antonio canta Flamenca, en un espacio rebosante de folclore.

El estadounidense es presentado en un espacio moderno y ampliamente abierto; y Antonio, que encarna la tradición folclórica, en un espacio cerrado y subterráneo. Tal contraste cultural se repite con los vehículos conducidos por ambos personajes. Sotelo presta a Merrit 
su descapotable en color plata brillante, un Pegaso Z-103, verdadero protagonista del film según Siegel (1996: 194) y considerado "el último gran coche español" (Gimeno, 1993: 51). Esta marca y estos modelos eran los más modernos de España y emulaban a los estadounidenses (Gimeno, 1993: 394). En contraste, Antonio conduce un totalmente negro Fiat 508C "Balilla", modelo familiar ya entonces pasado de moda, que no se fabricaba desde 1953. Con ambos personajes presentados en espacios y vehículos antagónicos, comienza el viaje.

\subsection{Propósitos del espacio}

Para proseguir analizando el resto de espacios se tiene en cuenta que "el modo, sobre todo la adjetivación emocional del espacio, contribuye a replantear el propósito" (Nieto Ferrando, Rey-Reguillo y Afinoguenova, 2015: 588), pues el espacio no se limita a propósitos previsibles, sino que puede incitar a los personajes a determinadas acciones. Como dicen Nieto Ferrando, Rey-Reguillo y Afinoguenova (2015: 589), el espacio "hace hacer". En el caso del protagonista, su profesión de arquitecto y el conflicto entre tradición y modernidad que vertebra la trama, dirigen la atención espacial hacia construcciones emblemáticas al inicio del trayecto. En Segovia (Fig. 4), Merrit queda fascinado con el acueducto, lo atraviesan con el vehículo por un arco y bajan para poder tocarlo.

Merrit demuestra conocer los fundamentos arquitectónicos, aunque realiza comentarios inclasificables entre la broma irónica y una parodia de ignorancia extranjera: "Él [Sotelo] que siempre está hablando de la tradición española ¿qué dice de este acueducto? Es un perfecto ejemplo, líneas simples, estilo funcional, sin decoración. Así quiero construir el hotel”. El desconocimiento de Mari es expuesto al señalar: "Nunca había podido comprender por qué no se caían todos estos pedruscos". Esto ocasiona una discusión por la presencia de turistas, que son los únicos que reparan en la construcción. Discusión que es aliviada frente al Alcázar: "Es mejor que Walt Disney", afirma Merrit, a lo que Mari añade "(...) y no parece una edificación funcional, como usted dice".

Figura 4. Fotogramas de Spanish Affair (Don Siegel, 1957)

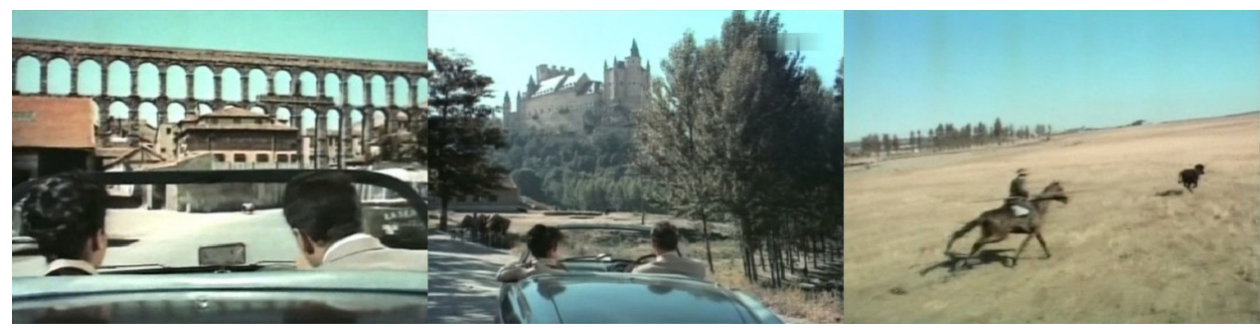

Fuente: Paramount Pictures Corporation (C)

Estas localizaciones llamativas y tradicionales hacen que los personajes actúen y dialoguen favoreciendo la trama, pues exponen sus posiciones sobre el conflicto entre tradición y modernidad. Los encuadres semisubjetivos, que incluyen simultáneamente vistas y vehículo, son constantes en las escenas de carretera y recogen tanto expresiones del cuerpo de 
los personajes como los espacios que contemplan. Sin más que atender en la ciudad, los personajes van a la dehesa del Conde, un amplio campo donde montan a caballo y tientan a un toro, actividades que refuerzan la imagen arcádica. En Barcelona, la única interacción importante con el espacio es en la plaza, donde los personajes participan en una sardana alrededor de la fuente. Cuando la lluvia interrumpe el baile, la gente se aglutina en un portal para refugiarse del agua, propiciando un abrazo de Merrit a Mari.

Otras localizaciones con incidencia narrativa son las escenas de carretera (Fig. 5). Conduciendo a Segovia, Merrit no puede esquivar a un campesino con su mula, que obstruyen la carretera. Mari resuelve el problema tocando la bocina insistentemente hasta que el hombre aparta. Al hacerlo, se abalanza sobre Merrit, propiciando su primer contacto físico. Avanzado el viaje, en las curvas peligrosas de Costa Brava, intentando esquivar las vacas de otro campesino, Merrit pierde el control del vehículo. Él entra en shock al rememorar el accidente en que murió su mujer y Mari lo atiende, consiguiendo que vuelva en sí. Cuando comentan lo ocurrido, él confiesa el sentimiento de culpa que arrastra e intiman en su relación. Estos eventos relacionados con el atraso social, pues son interferencias del entorno rural, implican un avance en la relación.

Figura 5. Fotogramas de Spanish Affair (Don Siegel, 1957)

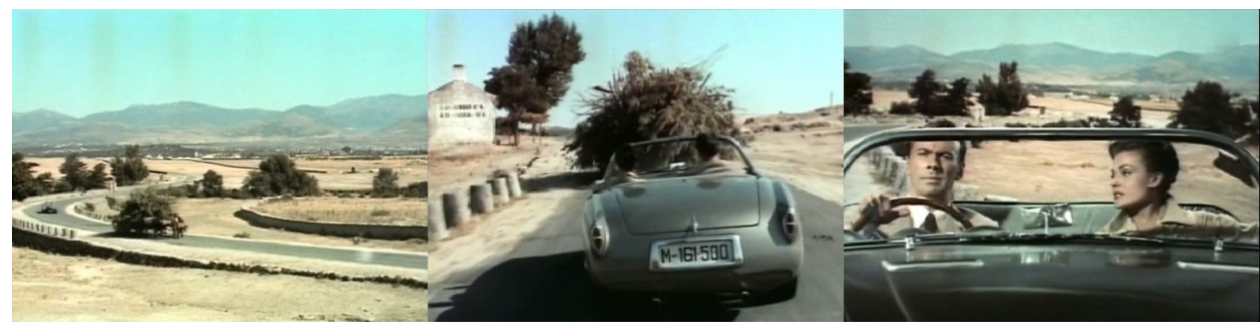

Fuente: Paramount Pictures Corporation (C)

El espacio en que la relación más profundiza es la playa de Tossa (Fig. 6), cuando Merrit y Mari se alejan de bañistas y pescadores buscando la intimidad que encuentran detrás del Castillo de Tossa. Durante el paseo romántico Mari canta la canción The Flaming Rose, se confiesan sus sentimientos y se besan escondidos en las ruinas de la Iglesia Gótica de San Vicent, no sin que Merrit sufra otro pequeño shock. El espacio también sirve de escondite a Antonio, que interrumpe a la pareja y exige a Mari en propiedad. Merrit impactado por lo rápido que ha pasado todo, niega estar enamorado de Mari. Ella, decepcionada, se va con Antonio y llegan a su cala gitana (Fig. 7), que rebosa folclore flamenco, pero también de niños mendigando y de familias pobres cenando sobre la tierra. Contrariada, Mari viaja Toledo para visitar a su padre y manifestarle que no se siente capaz de vivir con Antonio. 
Figura 6. Fotogramas de Spanish Affair (Don Siegel, 1957)

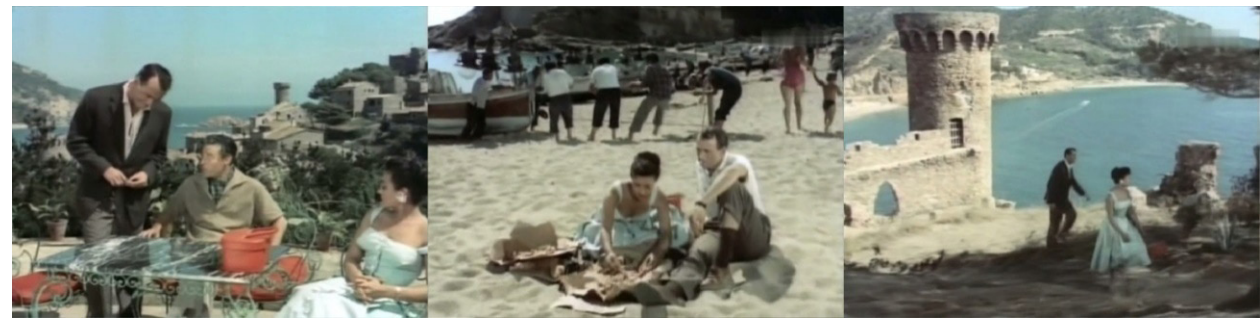

Fuente: Paramount Pictures Corporation (C)

Figura 7. Fotogramas de Spanish Affair (Don Siegel, 1957)

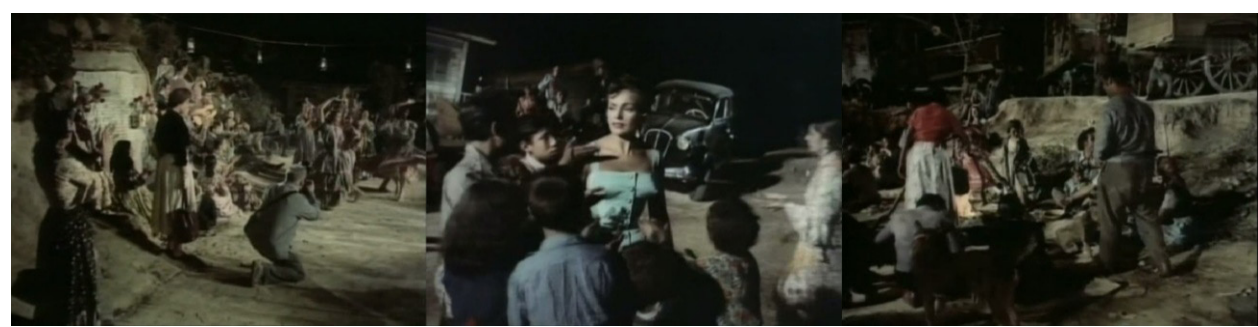

Fuente: Paramount Pictures Corporation (C)

Las escenas de Toledo (Fig. 8) comienzan con un plano situación, desde la terraza de un cigarral frente al Tajo, donde Mari regala una tarta de cumpleaños a su padre y baila una sevillana con el horizonte toledano de fondo. El protagonismo espacial de Toledo aumenta cuando, tras el reencuentro de Merrit y Mari, Antonio los persigue por la ciudad. Los callejones y tejados toledanos les permiten escabullirse y esconderse en las ruinas de una mezquita. A pesar de haber despistado a Antonio, Merrit decide dejar de esconderse y emerge de los escombros para plantarle cara. El enfrentamiento final, entorpecido por el estado del terreno, permite a Merrit demostrar el riesgo que está dispuesto a asumir por Mari. Finalmente, el puente de San Martín es telón de fondo de la declaración de amor a orillas del Tajo y del beso de Mari y Merrit que clausura el relato.

Figura 8. Fotogramas de Spanish Affair (Don Siegel, 1957)

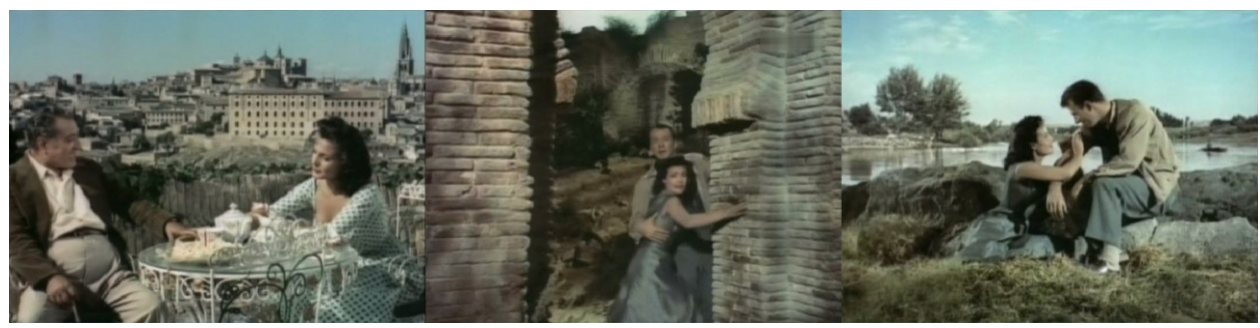

Fuente: Paramount Pictures Corporation (C) 


\subsection{Relación entre espacio y evolución de personajes}

Un criterio para definir los films turísticos es que "impliquen el desplazamiento o la estancia temporal en el destino turístico de alguno de sus personajes principales motivado total o parcialmente por el placer" (Nieto Ferrando, Rey-Reguillo y Afinoguenova, 2015: 592). $\mathrm{Al}$ inicio de Spanish Affair se menciona que Merrit iba a viajar por turismo con su esposa, pero tras fallecer ella, él mantuvo el viaje para cerrar el contrato de sus planos. Su viaje lo determina exclusivamente el trabajo, actitud en contraste con los personajes españoles, que aparcan sus oficios para descansar o veranear fuera de las grandes ciudades, o incluso pasear por el museo. Estas situaciones contrastan con la obsesión laboral de Merrit y son un elemento más relacionado con la cultura y el espacio, de los que se interponen en su objetivo, influyendo en su arco de transformación.

Otro criterio del film turístico es que el producto emplazado es el espacio. Rodríguez y Baños plantean sobre el emplazamiento en la trama del producto, que "las posibilidades de que $(. .$.$) se incremente su imagen por asociación a los personajes y situaciones narrativas,$ aumenta cuando se traspasa la simple presencia o utilización (...) para presentarse como elemento activo" (Rodríguez y Baños, 2010: 85). En el apartado se describen incidencias activas del espacio en la trama: los campesinos con ganado obstruyendo las carreteras, la pausa para contemplar el acueducto y el Alcázar, la tienta al toro que retrasa la reunión con el Conde, la sardana y el accidente en Tossa de Mar son situaciones generadas por el espacio, que propician reacciones en los personajes interfiriendo en el objetivo del protagonista, lo que plantea incidencias en la trama y el arco de transformación del protagonista.

Cuando Nieto Ferrando, Rey-Reguillo y Afinoguenova estudian la incidencia en la trama del espacio como producto emplazado, la relacionan con la evolución de los personajes y los puntos de giro. "Su presencia en las secuencias que componen las peripecias estructurales, más en concreto, y en este orden, en el primer y el segundo punto de giro (...) son más efectivas en el recuerdo del público que las emplazadas en otras secuencias" (Nieto Ferrando, Rey-Reguillo y Afinoguenova, 2015: 591). En la estructura narrativa de Spanish Affair el primer punto de giro estaría entre el acontecimiento desencadenante, el rechazo del proyecto, y el punto de ataque, que es cuando Merrit inicia el viaje por España. Este punto de giro divide los actos primero y segundo. Al iniciarse el segundo acto, el trayecto a Segovia dura dos breves escenas de carretera. Sin embargo, la reunión con el Conde Ribera es retrasada en varias ocasiones, extendiendo los eventos del segundo acto.

Primero una mula obstruye la carretera, después los protagonistas se detienen a contemplar el acueducto y el Alcázar, y ya en la dehesa del Conde, la reunión es retrasada por otras dos interacciones con el espacio: la persecución a caballo y la tienta del toro. Estos eventos no coinciden con el primer punto de giro, sino que se producen a continuación del mismo. Como productos emplazados estos espacios no ocuparían el momento idóneo, sino que entorpecerían la progresión narrativa, lo que lleva a entenderlos como digresión narrativa: "ralentiza el tiempo de la historia con planos descriptivos, planos de situación que permiten introducir vistas, (...) planos de carácter documental que asocian el espacio al folclore o las fiestas populares o secuencias musicales" (Nieto Ferrando, Rey-Reguillo y Afinoguenova, 2015: 607). 
En este sentido muchos espacios, por su atractivo visual o por características culturales, interfieren retrasando el objetivo inicial del protagonista, pero simultáneamente promueven el acercamiento amoroso. Cuando Mari presiona la bocina para avisar al campesino en la carretera, propicia su primer contacto con Merrit; ante el acueducto Merrit y Mari exponen sus posiciones enfrentadas; frente el Alcázar se reconcilian; intiman en la Sardana de Barcelona; el accidente de Costa Brava los une emocionalmente; la playa de Tossa facilita su primer beso; y la persecución por Toledo consolida la relación, huyendo juntos hasta la mezquita donde resuelven sus adversidades y Merrit supera su miedo a volver a amar. El espacio interviene simultáneamente en la negociación de los planos como digresión y en el romance imbricado narrativamente y ayudando a los protagonistas.

En cuanto a los efectos de promocionar un espacio como producto emplazado, "buena parte de las investigaciones sobre esta práctica publicitaria, sin embargo, insisten en su mayor efectividad si el emplazamiento aparece imbricado en la historia narrada" (Nieto Ferrando, Rey-Reguillo y Afinoguenova, 2015: 607). De acuerdo con esto, especialmente Toledo, pero también Tossa de Mar, serían los espacios más favorecidos como producto emplazado al estar imbricados en la trama. Estos espacios tienen una explícita función narrativa y dramática relacionada con la resolución en paralelo de ambas tramas al determinar el punto de giro final. Este giro final comienza cuando Merrit asume la inviabilidad de sus diseños y reconoce su amor por Mari; y se cierra cuando al enfrentarse a Antonio, Merrit le hace comprender que Mari y él están enamorados.

El espacio interviene paralelamente en la trama inicial y en el romance; y al hacerlo, invierte la relevancia de ambas, haciendo que la trama amorosa pase a ser la principal. Esta inversión de prioridades está relacionada con la evolución de Merrit. Éste es impaciente al inicio, pues prefiere salir cuanto antes con Mari, cuando Sotelo le proponía acompañarlo unos días más tarde; y prefiere cabalgar hasta donde se encuentra el Conde, cuando Mari le sugiere esperar en la entrada. En Barcelona Merrit comienza a disfrutar del entorno, al no poder realizar la visita a Oliva hasta el día siguiente. En Tossa de Mar, el buen clima permite improvisar un picnic en la playa, al que Merrit accede encantado pese a continuar pensando en el rechazo de su proyecto.

El espacio provoca que Merrit pase de aferrarse al trabajo, a disfrutar de momentos de descanso. Este punto de giro final se manifiesta cuando, antes de irse de Tossa, Merrit congenia en un bar con un marinero vasco. Conversan en tono filosófico sobre la falta de armonía que supondría para el entorno español una construcción moderna, pero no así con las personas: "Pero las casas no son hombres, o se adaptan o no se adaptan. El cemento y la piedra no tienen alma." El marinero también le aconseja insistentemente sobre los beneficios de la siesta, tras lo cual Merrit le da la razón, en lo de la siesta "y en muchas cosas". El acercamiento a Mari se produce después de que Merrit manifieste aprender lecciones de la cultura española y se deshaga de su obcecación arquitectónica.

A partir de Tossa de Mar, con el paisaje más arcádico e idílico del film, Merrit conoce mejor el territorio español y asume la inviabilidad de sus diseños. Esto encaja con lo que señalan 
Nieto Ferrando, Rey-Reguillo y Afinoguenova (2015: 607): “En muchos casos la vista turística es determinante para su evolución, y viene acompañada de anagnórisis esenciales en los arcos de transformación de algunos personajes", en este caso, del protagonista. En este film el espacio obstaculiza el objetivo del protagonista, pero las vistas turísticas no son adornos innecesarios, sino que inciden activamente en el arco de transformación de Merrit, tanto en renunciar a su proyecto y como en implicarse con Mari románticamente. Esto implica que el espacio interviene resolviendo el dilema vertebrador en favor de la tradición.

\section{Condicionantes de producción}

Como se señala al inicio de este artículo, la productora española CEA alegó la promoción de paisajes y monumentos españoles como motivación para la producción. Por parte estadounidense no está claro que hubiera interés turístico, pues a los productores Bruce Odlum y su padre Floyd Odlum no les pareció importante que Siegel no conociera España (Siegel, 1996, p. 191). Bruce había encargado el guion de Spanish Affair a Richard Collins, quien convenció a Odlum de ofrecer la dirección a su amigo Don Siegel, consiguiéndole su primer contrato de seis cifras (Siegel, 1996: 192) ${ }^{1}$. Hasta entonces Siegel era montador y un reputado director de cine independiente. Intentó convencer a Collins de mejorar el guion, pero éste contestó: "Bruce no me dejará hacer ni un cambio. Le encanta como está" (Siegel, 1996: 192). A Siegel no le agradaba aquella situación (Siegel, 1996: 193), pero la cuantía le inclinó a aceptar, siendo consciente de lo que había detrás: "Sospecho que todo fue una elaborada evasión de impuestos, por la que fui bien pagado” (Lovell, 1975: 54).

El interés estadounidense estaba en una maniobra económica. Este tipo de películas eran conocidas como Runaway productions, producciones desertoras. Las empresas estadounidenses no podían sacar sus ganancias de Europa a dólares. Si el dinero se invertía en grabar películas, el celuloide sí era exportable y podría devolver la inversión (Besas, 1985: 54). Esto sumado a la caída del cine clásico de Hollywood "impulsan, desde la mitad de la década, un cierto desplazamiento de la industria en busca de nuevos territorios donde abaratar los rodajes" (Fernández Heredero, 1993: 108).

Dichos fondos bloqueados y la disparidad salarial (León, 2010: 351), eran alicientes para realizar grandes producciones en Europa, dada la imposibilidad de muchas empresas estadounidenses de convertir a dólares sus ganancias en Europa (Guback, 1980: 346). A esto había que sumar la siguiente descripción en la que Spanish Affair es susceptible de ser incluida:

En ciertas películas declaradas en España como coproducciones, la aportación española se ha limitado a prestar servicio de información al productor extranjero, sirviéndole de guía en la elección de lugares de trabajo, contratación de personal secundario, etc. [...] Estas películas son las llamadas, en el argot comercial, coproducciones "marrón” (López y García Cuevas, 1955: 46).

${ }^{1}$ Estas "seis cifras" no concuerdan con las cinco cifras que el sueldo de Siegel fue declarado como en 30.000 dólares en la ficha técnica del permiso de rodaje. Por lo que Siegel debió ganar al menos más del triple del sueldo declarado en España. 
Como era habitual en las coproducciones de esa década, en la ficha técnica figura junto al director estadounidense, un codirector español, un "artificial hermano siamés” (Pérez-Perucha, 1990: 22). "CEA impuso como director adjunto y supervisor de sus intereses a Luis Marquina” (Pérez-Perucha, 1983: 74). Marquina estaba en ese preciso momento centrado en producción y retirado temporalmente de la dirección (Primer Plano, 5/X/1958: 8). A esto hay que añadir que "nunca mencionó esta película como suya” (Pérez Perucha, 1983: 74) y que los títulos acreditan a Siegel como único director, mientras Marquina figura como asistente de producción. Incluso un informe de censura aclara que permite el rodaje, siempre que se ajuste al guion modificado por los guionistas españoles Paso, Ozores y L. Marquina (AGA (3) 121.2 36/04769).

Para la parte estadounidense, la finalidad turística del film fue una garantía de que el proyecto sortease los obstáculos de los organismos de censura. Odlum prohibió cualquier modificación para acatar los informes de censura y no ver peligrar la maniobra financiera.

Con las correcciones introducidas por los guionistas españoles que han restado o casi suprimido toda la memez de los personajes, no encuentro inconveniente en proponer la aprobación, siempre que realmente se tengan en cuenta tales correcciones lo mismo en el rodaje de la película destinada a su explotación en España, que en el de los demás destinados a la explotación (AGA (3) 121.2 36/04769).

Las complacencias hacia la parte española están presentes en la renuncia del protagonista al individualismo, cediendo a los encantos de España siendo él quien se adapta a España y no al revés; y en detalles que, sin renunciar a los tópicos, disponen de la geografía española con bastante corrección. Pérez-Perucha (1983: 74) recuerda que Luis Marquina, "mantuvo feroz batalla contra los productores y Don Siegel" para evitar la españolada, en la que debió tener cierto éxito, pues sugiere que la sardana, "sobre todo recordando Noche fantástica (1943), la filmó él mismo o tuvo una destacada participación en su rodaje". Al margen de que el baile catalán fuese dirigido por Marquina o no, la inclusión de un componente cultural tan concreto obedece desde luego a la parte española. Más teniendo en cuenta que Siegel reconocía no conocer la cultura española, ni tampoco interés alguno en el conflicto entre tradición y modernidad.

\section{Discusión}

Aunque la finalidad turística de Spanish Affair no fuese motivación original de ambas partes productoras, encuadraba la producción dentro de los intereses del gobierno español. La promoción de espacios españoles encontrada en el film da más importancia visual a paisajes, pueblos y ciudades más arcádicos. Lo que inicialmente podría justificar las quejas de los representantes españoles en el extranjero. Los edificios madrileños y barceloneses no reciben especial énfasis visual, debido al poco juego que dan para la trama, mientras el acueducto y el Alcázar segovianos reciben atención visual explícita y detenida, y los paisajes de Tossa de Mar y Toledo con edificio en ruinas, están imbricados en la resolución de la trama y en su punto de giro final. 
Del análisis de propósito del espacio y su relación con la evolución de los personajes, se desprende que los primeros emplazamientos, con importante resonancia turística, sirven para describir a los personajes. Así, en Madrid son presentados Sotelo y Mari en el museo, Merrit en el aeropuerto y Antonio en el bar. En Segovia, Mari y Merrit exponen un debate entre arquitectura moderna y tradicional y el espacio funciona como digresión: las actividades en la finca segoviana, pernoctar en Barcelona antes de ir a Tossa de Mar y el incidente en Costa Brava, muestran elementos del territorio español alejando a Merrit de su objetivo empresarial y acercándolo al romance con Mari, que finalmente es sellado en Toledo, cuyos callejones y escombros los refugian de Antonio. La trama principal en busca de los socios y la secundaria sobre el romance de la pareja, intercambian su relevancia, por medio de las interacciones del espacio con los personajes.

En cuanto al conflicto planteado entre tradición y modernidad, éste es ganado por la tradición. Merrit fracasa en convencer a los socios para reconsiderar sus diseños y queda encantado con Mari y con los espacios españoles con que ella le presenta. Por el lado de Mari hay un acto de apertura y de renuncia a sus raíces gitanas, pero no cede ante la modernidad extranjera y el arco de transformación de ambos personajes no es equiparable. Mari renuncia a sus raíces gitanas, pero no a su vínculo con el territorio español, que es el verdadero triunfador y con el cual ella se identifica. Esta victoria del tradicionalismo puede entenderse como parte de las concesiones a las exigencias españolas.

En contra de las quejas enviadas, los detalles narrativos del film eran permitidos deliberadamente por el gobierno español y encajaban con la imagen arcádica-idílica de España generada en el propio cine español. Como señala León (2010: 353), “el gobierno español terminó tejiendo una [relación] entre la producción cinematográfica norteamericana y la promoción del turismo extranjero". Esto sumado a que los films turísticos españoles no tenían mucho recorrido comercial internacional (Nieto Ferrando, Rey-Reguillo y Afinoguenova, 2015: 586), permitir una película así era una posibilidad de tener algún control sobre la imagen turística de España en el cine internacional. Las modificaciones de Pazos, Ozores y Marquina habrían conseguido representar una España arcádica, pero con más detalles culturales españoles de lo usual en films estadounidenses.

\section{Conclusiones}

El territorio español funciona en Spanish Affair como elemento de digresión narrativa en la trama de negocios que lleva al protagonista Merrit a España, pues no coincide con los puntos de giro y ralentizan la consecución de sus objetivos. Hacia el final del film los espacios de Tossa y Toledo funcionan de manera imbricada en la historia de amor de Merrit y Mari. Por ello, como elemento activo, el espacio incide en ambos personajes haciendo que la trama principal y secundaria cambien sus papeles. Al pasar la trama romántica a ser la principal, el romance resuelve el conflicto entre tradición y modernidad.

Los datos de la Tabla 1 resaltan que los espacios arcádicos reciben más tiempo en pantalla que las grandes ciudades; conforman el retrato de una España rural, tradicional, socialmente atrasada, que no correspondería tanto a una imagen distorsionada desde el extranjero, 


\section{MHJournal Vol. 13 (1) | Año 2022 - Artículo no 3 (196) - Páginas 59 a 79 - mhjournal.org}

sino a la imagen de España que el Gobierno franquista buscaba promover en films extranjeros. Podría entenderse que tal traducción hizo el producto 'fallidamente' exportable, recordando que una de las quejas del embajador en Londres era la baja calidad reflejada en la crítica británica. Pero la principal causa de dicha baja calidad, bien podía provenir de la prioridad de la maniobra económica, que suponía a la parte estadounidense renunciar a criterios creativos, para no causar disgustos a la censura franquista.

Se buscó algo tan difícil como mantener las pretensiones españolas de fidelidad espacial tanto regional como cultural, y al mismo tiempo hacerla exportable, sin limitarse a los parámetros de Hollywood. Las quejas por permitir la difusión de esta imagen nefasta de España podían estar acertadas, en tanto España queda representada como un espacio atrasado y tradicional, incluso exótico, en el cual vivir aventuras, pero ello no se debía a prejuicios extranjeros, que a las autoridades franquistas se les pasar por alto, sino que, como señalan Nieto Ferrando, Rey-Reguillo y Afinoguenova (2015: 607), esa imagen arcádica-idílica de España era la tendencia del cine español de los años cincuenta.

\section{Bibliografía}

Baños González, M. Y Rodríguez García, T., (2010). Construcción y memoria del relato audiovisual, Madrid, Fragua.

Barjot, D. (2005). La aplicación del modelo norteamericano en Europa durante el siglo XX. En Delgado, L. y Elizalde, M. D. (eds.) (2005) España y Estados Unidos en el siglo XX. Madrid: CSIC, pp. 157-180.

Besas, P. (1985). Bebind the Spanish Lens. Spanish Cinema Under Fascism and Democracy. Denver: Arden Press.

Díez Puertas, E. (1996). El acuerdo cinematográfico hispano - norteamericano de 1952. Secuencias (4) pp. 9-38.

Gimeno Valledor, P. (1993): El automóvil en España, Madrid, Real Automóvil Club de España.

Guback, T. (1980). La industria internacional del cine. Madrid: Fundamentos.

Fernández Heredero, C. (1993), Las buellas del tiempo. Cine español 1951-1961, Valencia/Madrid: Filmoteca de la Generalitat Valenciana/Filmoteca Española.

León, P. (2010): Sospechosos habituales. El cine norteamericano, Estados Unidos y la España franquista, 1939-1960, Madrid, Consejo Superior de Investigaciones Científicas.

Lovell, A. (1975): Don Siegel. Londres: British Film Institute.

López, V. y García Cuevas, M. A. (1955): La industria de producción en películas en España. Madrid: Secretaría General del Movimiento. 
Martinez-Burgos, P. y Mingo Lorente, A. (2013): El Greco en el cine. Toledo: Celya.

Montero, J. A. y Niño, A. (2013). Guerra Fría y propaganda. Madrid: Biblioteca Nueva.

Nieto Ferrando, J., Del Rey Reguillo, A. y Afinoguenova, E. (2015): Narración, espacio y emplazamiento turístico en el cine español de ficción (1951 - 1977). Revista Latina de Comunicación Social, 70, pp. 584-610.

Pérez Perucha, J. (1983): El cinema de Luis Marquina. Valladolid: 28 Semana internacional de Valladolid.

Pérez Perucha, J. (1990): Mestizajes (Realizadores extranjeros en el cine español 1913-1973) Vol. I Ed. 11. Valencia: Mostra de Valencia.

Primer Plano, 5/X/1958.

Sevilla, C. (1993). Mis secretillos. Madrid: Blancur.

Siegel, D. (1996): A Siegel Film: an autobiography. Londres: Faber and Faber.

Vale, E. (1986): Técnicas de guion para cine y televisión. Barcelona: Gedisa.

Viñas, A. (2003): En las garras del águila. Los pactos con Estados Unidos, de Franco a Felipe Gonquález (1945-1995). Barcelona: Crítica.

\section{Archivo consultado:}

AGA: Archivo General de la Administración

\section{Filmografía:}

Odlum, B. (productor), y Siegel, D. (director). (1957). Spanish Affair. EE.UU. y España: Nomad, Benito Perojo y Cinematografía Española Americana.

\section{Uso de imágenes}

Las imágenes utilizadas como figuras en este artículo son elementos centrales del análisis, realizado únicamente con fines científicos en el ámbito académico. 
MHJournal Vol. 13 (1) | Año 2022 - Artículo no 3 (196) - Páginas 59 a 79 - mhjournal.org

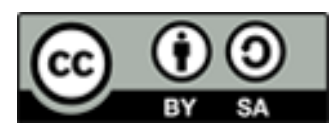

Licencia Creative Commons

Miguel Hernández Communication Journal

mhjournal.org

\section{Cómo citar este texto:}

Luis N. Sanguinet (2022): El espacio arcádico idílico en la España de Spanish Affair, en Miguel Hernández Communication Journal, Vol. 13 (1), pp. 59 a 79. Universidad Miguel Hernández, UMH (Elche-Alicante). DOI: 10.21134/mhjournal.v13i.1449 